\title{
AJARAN TASAWUF TAREKAT TIJANIYAH
}

\section{Noor'ainah}

Fakultas Ushuluddin IAIN Antasari Jl. A. Yani Km. 4,5 Banjarmasin

Diterima 20 Juli 2010/Disetujui 14 September 2010

\begin{abstract}
Abstrak
Tarekat adalah jalan atau petunjuk dalam melaksanakan suatu ibadah sesuai dengan ajaran yang dibawa oleh Rasulullah saw. dan dicontobkan oleh beliau, para sahabat, tabii dan tabi' tabi'in. Lewat ajarannya tentang proses tabiyah rubiab (pendidikan rubani) dapat dilihat tarekatnya sebagai upaya meraih posisi warasat al-anbiya (pewaris para nabi). Tampilnya seorang sufi di tengah masyarakat merupakan bentuk lain dari ketaatannya pada Allah dan rasul-Nya. Peranan para sufi begitu penting dalam kehidupan masyarakat dalam melakukan dakwah Islam. Para sufi tidak selayaknya jika hanya mementingkan kontemplasi dan zikr, lantas mengabaikan masyarakat yang memerlukan bimbingan.
\end{abstract}

Kata kunci: ajaran tasawnf, tarekat tijaniyah, tarbiyah rubiah

\section{Pendahuluan}

Tarekat adalah jalan atau petunjuk dalam melaksanakan suatu ibadah sesuai dengan ajaran yang dibawa oleh Rasulullah saw. dan dicontohkan oleh beliau, para sahabat, tabi'i dan tabi' tabi'in. ${ }^{1}$ Umarie Barmawi mengungkapkan pengertian tarekat adalah jalan atau sistem yang ditempuh menuju keridhaan Allah semata, sedang usaha menempuh jalan itu bernama suluk, dan orangnya bernama salik. ${ }^{2}$ Laily Mansur menyatakan tarekat merupakan usaha pencapaian pengalaman batin yang dilaksanakan dengan cara dan aturan praktis, penuh disiplin dengan tujuan mendekatkan diri kepada Allah di bawah bimbingan seorang syekh. ${ }^{3}$

${ }^{1}$ Muhamad Saifulllah, al-Aziz Senali, Tasawuf dan Jalan Hidup bagi Para Wali, Gresik, (Jawa Timur: Putra Pelajar, 2000), h. 32.

${ }^{2}$ Bermawi Umarie, Sistematika Tasawuf, (Solo: Ramadhani, 1987), h. 116.

${ }^{3}$ H.M.Laily Mansur, Tasawnf Islam, mengenal Aliran dan Ajaran, (Banjarmasin: Unlam Press, 1992), h. 103-104. 
Jadi tarekat adalah suatu cara atau jalan yang ditempuh oleh para ahli tasawuf atau kaum mutasawwifin untuk mencapai tujuan, sebagaimana yang dijelaskan oleh Syekh Zainuddin bin Ali "tarekat adalah menjalankan amal dengan lebih berhati-hati dan tidak memilih kemurahan (keringanan) syara' seperti sifat wara'serta ketetapan hati yang kuat seperti latihan-latihan jiwa. ${ }^{4}$

Tarekat bermula dari tasawuf yang kemudian berkembang dengan berbagai macam paham dan aliran. ${ }^{5}$ Sedang pengertian Tasawuf itu sendiri secara umum adalah usaha untuk mendekatkan diri kepada Allah dengan sedekat mungkin melalui kesucian rohani dalam memperbanyak ibadah. ${ }^{6}$ Untuk mendekatkan diri kepada Allah dalam tarekat diperlukan adanya bimbingan seorang guru/syekh, sebab bagi yang beribadah tanpa bimbingan guru/pembimbing, berarti dia dibimbing orang ketiga, orang ketiga dimaksud adalah setan.

Tarekat Tijaniyah disampaikan pertama kali oleh Syekh Ahmad alTijani (w. 1230H/1815H). ${ }^{7}$ Tarekat ini bermula dari Berber Al-jazair dan menyebar dari al-Jazair ke selatan Sahara, terus masuk ke Sudan bagian Barat dan Tengah, Mesir, Senegal, Afrika Barat, Nigeria, dan bahkan tarekat ini sudah diperkenalkan sampai ke Amerika Barat dan Utara. ${ }^{8}$ Tijaniyah termasuk tarekat muktabarah yang diakui keberadaan dan kebenarannya di Indonesia. ${ }^{9}$

Nama Tijaniyah ini dinisbatkan kepada keluarga ibunya, dan disebut juga dengan tarekat al-Ahmadiyah, ${ }^{10}$ tarekat ini tidak diketahui secara pasti

${ }^{4}$ Muhamad Saifullah al-Aziz Senali, Tasawuf dan Jalan bidup bagi para Wali, (Gresik Jawa Timur: Putra Pelajar, 2000), h. 32.

${ }^{5}$ PPTA IAIN Sumatera Utara, Pengantar Ilmu Tasamuf, (Medan: PPTA IAIN, 1983), h. 274.

${ }^{6}$ Projodikoro, Jama'ah pengajian tarekat Islamiyah LempuyanganYogyakarta dalam Jurnal Penelitian Agama no 15 Th VI, Januari-April 1997, (Yogyakarta: Balit P3M IAIN Sunan Kalijaga, 1997), h. 13.

${ }^{7}$ H.M. Laily Mansur, Ajaran dan Teladan Para Sufi, (Jakarta, PT Raja Grafindo Persada, 1999), h. 285.

${ }^{8}$ Syekh Fadlullah Haeri, Belajar Mudah Tasawnf, terj. oleh Muhamad Hasyim Assegaf, (Jakarta: PT Lentera Basritama, 1994), h. 29.

${ }^{9}$ Musyawarah nahdhiyyin di Pekalongan Jawa Timur tanggal 26-28 Pebruari 2000 menetapkan bahwa ada 46 nama tarekat yang dianggap mu'tabarah, dan salah satunya adalah tarekat Tijaniyah.

${ }^{10}$ Muhammad bin Abdullah bin Husnain, Al-Fath al-Rabbany fî̀ Ma Yabtaju Ilaibi l-Murîd al-Tijani, (Surabaya: Maktabah Sa'ad bin Nashir bin Nabhan, t.th.), h. 4. Lihat pada H. Abu Bakar Aceh, Pengantar Ilmu Tarekat, (uraian ttg Mistik), (Solo: Ramadhani, 1994), h. 374. 
kapan sampai ke Indonesia dan siapa yang membawanya. Namun yang tercatat dalam sejarah bahwa ditahun 1928 telah terjadi gerakan (kegiatan tarekat) di Cerebon. Seorang Arab yang tinggal di Tasikmalaya bernama Ali bin Abdullah al-Thayyib al-Azhari berasal dari Madinah menulis sebuah kitab “Munyatul Murid”, berisi tentang beberapa petunjuk dan ajaran Tarekat Tijaniyah. Juga di tahun 1934 dalam "Pragmenta Islamica" di Leiden terdapat hasil penyelidikan Dr. G.F. Pijper terhadap kegiatan tarekat Tijaniyah di Indonesia atau Cerebon. Dari bukti sejarah ini berarti tarekat Tijaniyah ini berada di Indonesia minimal sejak tahun 1928 tersebut.

Secara genetik Ahmad al-Tijani mempunyai hubungan darah dengan Nabi saw. ${ }^{11}$ mempunyai jiwa yang gemar terhadap ilmu, sehinggga tidak mengherankan dikemudian waktu ia menjadi sufi yang termasyhur dan berhasil dengan tarekatnya.

\section{Sekilas tentang Sosok Pribadi Syekh Ahmad al-Tijani}

Syekh Ahmad al-Tijani adalah pendiri tarekat Tijaniyah, berasal dari Algeria (marokko) bernama lengkap Abu al-Abbas Ahmad bin Muhammad (Abi Amr) ibn Mukhtar bin Ahmad bin Salim bin al'id ibn Salim bin Ahmad (Ulwani) ibn Ahmad bin Ali bin Abdullah bin Abbas ibn Abdul Jabbar bin Idris bin Ishak bin Zainal Abidin bin Ahmad bin Muhammad (al-Nafs al-Zakiyah) ibn Abdillah al-Kamil ibn Hasan alMutsanna ibn Hasan al-Sabth bin Ali bin Abi Thalib dari Fatimah al-Zahra binti Muhammad bin Abdullah Rasulullah saw. ${ }^{12}$ sedang dari pihak ibunya, Ahmad al-Tijani adalah Aisyah binti Jalil Abi Abdilllah Muhammad bin Sanusi at-Tijani al-Madhawi. Dari sinilah nama Tijani diambil, yaitu dari qabilab yang terkenal saat itu yaitu Tijanah. ${ }^{13}$

Ahmad al-Tijani lahir pada tahun 1150 H (1737-8 M) di desa 'Ain Madhi. Kampung ini letaknya di Gurun Sahara bagian timur negara Magrib, yaitu di sebelah selatan al-Jazair. Pada awalnya ia berguru kepada orang tuanya dan guru-guru di daerahnya. Di usia tujuh tahun Ahmad al-Tijani

\footnotetext{
${ }^{11}$ Noer Iskandar al-Barsany, Tasawnf Tarekat dan Para Sufi, (Jakarta: Srigunting Raja Grafindo Persada, 2001), h. 90.

${ }^{12}$ Muhammad bin Abdullah, Al-Fath al-Rabbany...., h. 7

${ }^{13}$ Muhammad bin Abdullah, Al-Fath al-Rabbany...., h. 7
} 
sudah hafal al-Qur'an secara keseluruhan. Pada tahun 1166 H. Ayah dan ibunya meninggal pada hari yang sama dikarenakan wabah (cacar/panas), jadilah dia sebatangkara padahal usianya masih sangat muda (16 tahun). Sepeninggal orang tuanya Ahmad al-Tijani tinggal bersama saudara ibunya sampai usianya 21 tahun. Setelah itu Ahmad al-Tijani mengembara mencari ilmu keberbagai daerah. Di tahun $1186 \mathrm{H}$ dia berangkat ke Mekkah untuk menunaikan ibadah haji dan berziarah ke makam Rasulullah saw. di Madinah. Di kota ini Ahmad al-Tijani banyak berguru menimba ilmu-ilmu agama, juga ilmu yang berkaitan dengan ilmu rahasia bathin (asrâr). Berkaitan dengan ilmu asrar ini Ahmad al-Tijani berguru kepada Muhammad bin Abdul Karim al-Samman, pendiri tarekat Sammaniyah.

Ketika Ahmad al-Tijani berusia 50 tahun $(1200 \mathrm{H})$ beliau bertemu lagi dengan Rasulullah saw dalam kasyfnya dan menyempurnakan amaliah/ wiridan yang pernah diberikan, yaitu dengan menambahkan seratus kali zi ikir Hailalah. Semenjak itu Ahmad al-Tijani mengajarkan wirid, zikir, shalawat, istigfar dan do'a yang diterimanya dari Rasulullah saw. kepada muridmuridnya. Pada tahun $1213 \mathrm{H}$, Ahmad al-Tijani pergi dan pindah ke kota Fez (Marokko) dan menetap disini mengajarkan tarekatnya. Akhirnya di usianya yang ke 80 tahun bertepatan tanggal 17 Syawal $1230 \mathrm{H}$ atau 22 September 1815 M dia meninggal pada hari Kamis, sesudah shalat Subuh, berbaring di bahu kanan dan dengan tenang menghadap Allah, dan dimakamkan di Fez. ${ }^{14}$

\section{Ajaran Tarekat Ahmad al-Tijani}

Berbeda dengan tarekat-tarekat lain, tarekat Tijaniyah ini tidak mempunyai silsilah tarekat, sebab sebagaimana telah diungkapkan di atas bahwa Ahmad al-Tijani menerima ini semua langsung dari Rasulullah saw. Ajaran yang sederhana dan relatif mudah. Sebab tujuannya adalah mendekatkan diri kepada Allah, memperoleh ampunan dan ridha-Nya.

Tarekat Tijaniyah tidak mengenal mursyid, tapi mereka mengenal istilah muqaddam dan khalifah. Pengikutnya tidak dibenarkan berpolitik praktis, sebab hal itu identik dengan permusuhan, persaingan atau kebencian. Hidup bersih dan makanan halal adalah sesuatu hal yang harus diprioritaskan,

\footnotetext{
${ }^{14}$ Muhammad bin Abdullah, Al-Fath al-Rabbany...., h. 6-10.
} 
karena kebersihan jasmani berpengaruh kepada bathin/rohani. Untuk menghasilkan hati bersih, makanan serta faktor pendukung (finansial) pun harus bersih dan halal. Tanpa itu tabir ilabiyah sulit terungkap. ${ }^{15}$

Dalam Tarekat Tijaniyah ada beberapa persyaratan penting yang harus dipenuhi dan diperpegangi oleh pengikutnya, yaitu: 1). Melazimkan shalat fardhu dalam waktunya dengan memelihara syarat, rukun dan segala adabnya yang sunat-sunat. Utama sekali berjamaah; 2). Taqwa kepada Allah dengan zahir dan batin sesuai kemampuan. Jika terjadi pelanggaran syar'i wajib segera bertaubat kepada Allah; 3). Tidak ziarah untuk minta madad rohani (seperti minta do'akan) kepada waliullah yang bukan dari Tijaniyah dan sahabat Rasulullah saw. baik yang sudah mati maupun yang masih hidup. Tetapi wajib memuliakan waliullah (jangan diremehkan); 4). Tidak mengumpulkan tarekat ini dengan tarekat lainnya; dan 5). Bersedia mengamalkan ajaran tarekat ini sampai akhir hayatnya.

Di samping persyaratan di atas, ada beberapa hal yang berkaitan dengan kesempurnaan pengikut tarekat ini, yaitu: 1). Yakin bahwa Ahmad al-Tijani melihat atau bertemu Rasululllah saw dalam keadaan sadar, jaga, bukan melalui mimpi; 2). Hadirnya Rasulullah saw dan sahabat serta Ahmad al-Tijani ketika membaca Jauharat al Kamal dihitungan bacaan kali ketujuh; 3). Menggunakan harum-haruman ketika membaca Jaubarat al-Kamal dan dianjurkan berkelompok sekitar 6 orang dengan duduk diatas hamparan kain; 4). Haruslah berwudhu sebelum membaca Jauharat al-Kamal; 5). Suci dari hadas besar dan kecil ketika membaca wirid; 6). Membaca tasbih dikala ruku' dan sujud disyaratkan tiga kali dan harus dibaca secara tartil; 7). Membaca basmalah dengan jelas (agak nyaring) dibacaan al-fatihah di dalam shalat fardhu; 7). Ahmad al-Tijani adalah al-Qutb al-Maktum wa al-Khatim al-Muhammadiy al-Malum; 8). Penutup para wali; 9). Pancaran Ilahi (al-faidh) memancar dari zat Sayyid al-Wujud Mubammad saw terus ke Ahmad al-Tijani untuk seluruh makhluk; 10). Membaca salawat fatib sekali sebanding dengan enam kali membaca al-Qur'an; dan 11). Larangan menziarahi wali-wali lain dengan maksud mengambil wirid darinya. ${ }^{16}$

\footnotetext{
${ }^{15}$ Republika, terbit hari Jum'at, 31 Mei 2002.

${ }^{16}$ Muhammad bin Abdullah, Al-Fath al-Rabbany...., h. 10-38.
} 
Dalam Tarekat Tijaniyah terdapat tiga pokok amalan wirid (bacaan yang diamalkan/dibaca secara rutin), yaitu: Pertama, Wirid lazimah, wirid ini dilaksanakan setiap pagi hari mulai selesai shalat subuh sampai datangnya waktu dhuha, dan sore hari, mulai selesai melaksanakan shalat ashar sampai datangnya waktu isya. Rangkaian wirid lazimah yang menjadi rukunnya hanyalah istigfar, salawat dan zikir, masing-masing 100 kali' sedangkan bacaan lainnya termasuk dalam keutamaan (al-fadhail).

Dalam Jawabir al-Ma'ani dikatakan bahwa tiga bentuk wirid tersebut merupakan satu kesatuan yang utuh, dalam arti masing-masing melengkapi satu sama lain. Bacaan istigfar misalnya dimaksudkan atau berfungsi membersihkan diri dari kotoran maksiat. Sebab pada dasarnya tujuan masuk tarekat ialah mendekatkan diri kepada Allah swt. ${ }^{17}$ Oleh karena itu terlebih dahulu murid harus beristigfar sebagai pembersih dan pensuci dosa.

Bacaan salawat dimaksudkan untuk mendekatkan diri kepada makhluk yang dicintai Allah swt yaitu Nabi Muhammad saw. beliau adalah makhluk yang mendapat gelar habib Allah. Allah memerintahkan umat beriman agar membaca salawat kepada Nabi Muhammad saw. begitu pula para malaikat juga diperintahkan untuk bersalawat atas Nabi Muhammad saw.

Posisi Nabi Muhammad saw adalah makhluk yang diistemewakan oleh Allah swt. Ahmad al-Tijani menyebutnya sebagai makhluk yang paling ma'rifah (mengenal Allah) dan paling dekat pada Allah swt. ${ }^{18}$ Karena itu untuk menghadap dan menuju Allah swt terlebih dahulu murid harus mendekatkan diri kepada beliau dengan cara membaca salawat. Selain itu membaca salawat merupakan sarana untuk meraih rahmat Allah swt. Adapun zikir lâ ilâha illa allâh dibaca oleh murid setelah bersih dan suci melalui bacaan istigfar dan mendekatkan diri kepada pembimbing utama, yakni Nabi Muhammad saw., selanjutnya ia menuju benteng Allah swt dengan zikir melalui bacaan la ilaha illa Allah.

Pola istigfar yang diajarkan oleh Nabi Muhammad saw. sebagaimana yang terdapat dalam hadis-hadis sahih, ada dua; pola yang diakhiri dengan kalimat wa atûbu ilaibi (aku bertobat kepada Allah), dan yang tidak diakhiri

${ }^{17}$ Ali Harazim, Jawahir al-Ma'ani wa Bulug al-Ma'ani, (Mesir: Musthafa al-Babi al-Halabi, 1985), h. 102

${ }^{18}$ Ali Harazim, Jawahir al-Ma'âni...., h. 197. 
dengan kalimat itu. Amalan Tarekat Tijaniyah mempergunakan pola yang kedua, yaitu yang tidak disertai kalimat tersebut. Dalam Fath al-Rabbani dikatakan bahwa hal ini merupakan upaya penyelamatan diri dari dosa yang timbul dari bacaan istigfar itu sendiri, sebab menurutnya, tambahan kalimat tersebut mengandung arti bahwa orang yang membaca istigfar tersebut telah mengklaim dirinya sebagai orang yang melaksanakan taubat. Apabila dalam kenyataannya ia tidak melaksanakan taubat dengan sungguhsungguh, misalnya ia tetap melaksanakan maksiat kepada Allah, dengan sendirinya secara tidak disadari ia telah melakukan dosa dari dua sisi; dosa dari perbuatan maksiat itu sendiri, dan dosa dari bacaan istigfarnya. Pola istigfar tanpa kalimat wa atûbu ilaibi, ia tidak mempunyai beban apa-apa dari bacaannya, sebab ia hanya minta ampun kepada Allah. ${ }^{19}$

Maksud istigfar adalah membersihkan diri dari kotoran-kotoran maksiat hati, dan dari kotoran tingkah laku lahiriah yang menyimpang dari aturan syari'at. Pembacaan istigfar menurut Ahmad al-Tijani sudah mengandung pengertian melaksanakan taubat, sebab taubat itu menurut beliau mengembalikan diri dari kekufuran terhadap nikmat Allah, memperlihatkan sikap syukur kepada Allah dengan jalan melaksanakan segala perintah-Nya. Membersihkan diri dari sikap menyepelekan kewajiban syara', dan dari perbuatan yang dilarang oleh syara'. ${ }^{20}$ Dengan kata lain, taubat adalah kembali kepada Allah dengan jalan melaksanakan syari'at Islam. Sebab pada dasarnya perjalanan yang harus ditempuh oleh seorang murid menuju Allah sejak langkah awal sampai akhir harus menjalankan syariat. Tidak mungkin seseorang sampai (wusul) kepada Allah tanpa dasar syari'at.

Untuk tercapainya pelaksanaan taubat, murid harus melaksanakan halhal berikut ini: melepaskan diri dari perbuatan dosa, merasa sedih terhadap perbuatan dosa yang dilakukannya, mempunyai maksud yang kuat untuk tidak kembali pada perbuatan maksiat, mempunyai tekad yang kuat untuk senantiasa beribadah kepada Allah dan merasa takut untuk tidak mensyukuri nikmat-Nya.

Untuk terwujudnya syarat taubat tadi, ada beberapa adab/ketentuan yang harus dilaksakan, yaitu: Menghindar dari orang-orang yang senantiasa

${ }^{19}$ Muhammad bin Abdullah, Al-Fath al-Rabbany...., h. 70.

${ }^{20}$ Ali Harazim, Jawahir al-Ma'ani...., h. 9. 
melaksanakan perbuatan maksiat dan orang-orang yang mempunyai tabiat yang jelek, bahkan murid harus senantiasa bergaul dengan orang-orang yang taat melaksanakan kebaikan, menjauhi tempat-tempat keramaian yang tidak berguna dan tempat-tempat yang mengundang maksiat, dan tidak boleh banyak mengungkapkan kenikmatan nafsu syahwat. ${ }^{21}$

Aspek bacaan salawat dalam wirid ini, kurang mendapat penekanan. Membaca salawat berfungsi li al-Tabarruk (untuk mendapatkan barkah) dan wasilah (perantara) supaya bacaan istigfar dan segala ketentuannya diterima oleh Allah swt. Ahmad al-Tijani mengatakan bahwa wasilah (perantara) yang utama untuk bisa wusul (sampai) terhadap Allah adalah nabi Muhammad saw. untuk dekat dengan Nabi Muhammad saw. adalah melalui bacaan salawat. Keyakinan ini didasarkan atas atsar (perkataan sahabat) Umar Ibnu al-Khattab yang menyatakan “ berkata Umar ibnu al-Khattab: Do'a seorang hamba ditangguhkan antara langit dan bumi, sampai dibacakan salawat kepada Nabi Muhammad saw."

Sebagaimana halnya bacaan salawat, dalam wirid lazimah, bacaan zikir juga kurang mendapat tekanan. Dalam wirid ini qikir dimaksudkan untuk menyatakan taubat yang sungguh-sungguh, sehingga dengan ucapan lailahaa illa allah (tidak ada Tuhan selain Allah), murid seolah-olah mengatakan la yagfiru zunnuba illa allah (tidak ada yang menghapus dosa kecuali Allah). ${ }^{22}$ Selain itu, dengan mengamalkan zikir dalam wirid lazimah, diharapkan murid akan merasa sakit batinnya apabila tidak mempunyai kesempatan untuk berbuat baik, dan selanjutnya akan melakukan introspeksi (al-mubasabab) dengan harapan bisa memperbaiki keadaannya dan sekaligus memelihara taubatnya dengan segala amal syari'at. ${ }^{23}$

Di dalam tarekat Tijaniyah, murid dalam proses pendidikan ruhani (tarbiyah) harus menempuh perjalanan panjang dan penuh tantangan. Dalam tarekat Tijaniyah dikenal dua katagori murid. Pertama, murid dalam katagori umum, yakni murid yang hanya diberi petunjuk-petunjuk umum mengenai amalan dasar, syarat dan peraturan yang terdapat dalam tarekat Tijaniyah,

${ }^{21}$ Sayyid Ubaidah, Mizab al-Rahmah fi al-Tarbiyah li al-Tarekat al-Tijaniyah, (Mesir: Maktabah Abd al-Hamid Ahmad, t.,th), h. 94.

${ }^{22}$ Sayyid Ubaidah, Mizab al-Rahmah...., h. 65.

${ }^{23}$ Sayyid Ubaidah, Mizab al-Rahmah...., h. 96. 
tanpa harus mengikuti aturan-aturan khusus dalam proses tarbiyah tarekat. Garis besarnya, murid dalam katagori ini hanya mempunyai tujuan mendapatkan berkah dan atau mendapatkan pahala dari amalan tarekatnya. Kedua, murid dalam katagori khusus, yakni yang mengikuti aturan-aturan proses tarbiyah yang terdapat dalam tarekat Tijaniyah. Murid dalam katagori ini diarahkan untuk berada sedekat mungkin dengan Tuhan dan atau memperoleh cahaya ma'rifah. ${ }^{24}$

Penjelasan di atas, mengantarkan pada suatu pemahaman bahwa murid tarekat Tijaniyah dalam katagori pertama bisa dilakukan oleh umat Islam secara umum, yang terpenting mereka mempunyai keinginan untuk melaksanakan ketentuan-ketentuan umum tarekat ini, tanpa harus mengikuti disiplin latihan ruhaniyah secara khusus. Dengan demikian mereka hanya menyentuh permukaannya saja dari tarekat Tijaniyah. Sedangkan murid dalam katagori kedua, harus disiplin menjalankan latihan ruhaniyah secara intensif, sebab mereka akan menembus kepada kedalaman tarekat Tijaniyah. Meski demikian, tarekat Tijaniyah dalam mendidik, mengarahkan dan memelihara muridnya yang dalam tradisi tarekat ini disebut ikhwan (saudara), atau abl (keluarga) tarekat Tijaniyah, menpunyai syarat dan peraturan umum yang harus dipatuhi oleh setiap murid yakni mengosongkan amal wirid yang lain. Ahmad al-Tijani mengatakan bahwa muridnya haruslah terlebih dahulu mengosongkan amalan wirid yang telah diterima dari syekh atau guru yang lain. ${ }^{25}$

Suatu keharusan bagi pengikut tarekat Tijaniyah harus mengosongkan diri dari wirid yang lain. Yang dimaksud dengan "mengosongkan amal wirid yang lain" adalah bukan amal wirid yang terdapat dalam hadis-hadis Rasulullah saw. sebab amalan-amalan wirid yang biasa di amalkan oleh Rasulullah saw sangat dianjurkan dalam tarekat Tijaniyah. Adapun yang perlu dikosongkan itu adalah amalan wirid tarekat yang telah didapat dari syekh/guru yang lain. Karena setiap tarekat punya amalan-amalan. Ada yang punya kekhususan seperti tarekat Tijaniyah dan pula yang amalan yang umum dilakukan banyak orang sesuai dengan sabda atau hadis Rasulullah saw. Jelasnya tarekat Tijaniyah mengkhususkan untuk calon murid

\footnotetext{
${ }^{24}$ Sayyid Ubaidah, Mizab al-Rahmah...., h. 88.

${ }^{25}$ Muhammad bin Abdullah, Al-Fath al-Rabbany...., h. 45.
} 
(pengikutnya) agar sebelum mengamalkan wirid tarekat Tijaniyah, amalan wirid yang dia punya sebelumnya harus ditinggalkan. ${ }^{26}$ Adapun wirid yang tidak termasuk ikatan tarekat seperti hiz̨b dan wirid-wirid lain terutama salawat boleh diamalkan oleh ikhwan Tijani.

Di dalam Rimah, diungkapkan bahwa tarekat dan segala syarat dan peraturannya dan apa saja yang terdapat di dalamnya semuanya berdasarkan syariat. Adapun yang kelihatannya bertentangan dengan syari'at, hal ini dikarenakan adanya sisi penglihatan yang berbeda terhadap metode amalan tasawuf. ${ }^{27}$ Ungkapan dan penjelasan di atas, secara tersirat menjelaskan bahwa peraturan mengosongkan amalan tarekat, tidak berarti tarekat yang lain salah, akan tetapi, hal ini dimaksudkan supaya murid lebih terkonsentrasi pada satu ajaran.

Kedua, Wirid Warifah ${ }^{28}$ adalah amalan yang dilaksanakan satu kali dalam sehari semalam. Apabila dalam wirid lazimah aspek bacaan istigfar dengan berbagai ketentuannya mendapat tekanan yang sangat besar, maka dalam wirid wazifah penekanan lebih ditujukan kepada aspek bacaan salawat. Tidaklah mengherankan, sebab dalam wirid ini terdapat dua bentuk salawat yang tidak terdapat dalam wirid lazimah. Kedua bentuk salawat dimaksud adalah salawat al-fatih dan salawat jaubarat al-kamal.

Kaitannya dengan bacaan salawat dalam wirid wazifah terdapat dua aspek penekanan yaitu aspek syukur ${ }^{29}$ yang didasarkan pada posisi Nabi Muhammad saw. sebagai al-fatih lima ugliq dan aspek mahabbah (cinta). Aspek syukur dengan membaca salawat bagi murid mempunyai dasar mababbah terhadap Nabi Muhammad saw dibuktikan dalam amalan salawat, sebab pada dasarnya mahabbah itu sendiri mempunyai arti yang sangat besar dalam membina hubungan yang berkesinambungan dengan Nabi Muhamad saw.

Ahmad al-Tijani mengemukakan, bahwa mahabbah itu sendiri harus diikuti dengan mengamalkam sunnahnya, petunjuknya, dan mengikuti seluruh perjalanan hidupnya. Dalam Jawahir al-ma'âni dikatakan: "mababbah

${ }^{26}$ Umar al-Futi, Rimah fi Hiæb al-Rahim, (Mesir: Mustafa al-Babi al-Halabi, t.th.), h. 125

${ }^{27}$ Umar al-Futi, Rimab fi Hiz̧b...., h. 105.

${ }^{28}$ Wazifah (bahasa arab) berasal dari kata wazafa yang berarti menetapkan. Sedangkan wazifah berarti tugas atau fungsi. Wirid Warifah berarti ketetapan wirid bagi setiap murid Ahmad al-Tijani.

${ }^{29}$ Ali Harazim, Jawahir al-Ma'ani...., h. 126. 
kepada Allah harus dibuktikan dengan mengikuti kekasih -Nya (Nabi Muhammad saw) secara lahir dan bathin, membenarkan seluruh beritanya, taat terhadap seluruh perintahnya, memenuhi segala panggilannya. Mahabbah tersebut dimaksudkan mencintai rasul dijadikan sebagai obat hati sanubari, istirahatnya jiwa, dan merupakan kenikmatan ruh. ${ }^{30}$ Membaca salawat kepada Nabi saw pada dasarnya mengandung makna cinta, mengagungkan, dan diikuti dengan melaksanakan sunnah secara total. Mengikuti rasul merupakan tanda mahabbah seseorang terhadap Tuhannya.

Tanda-tanda bahwa murid yang bersangkutan mencintai Rasul saw. (mahabbah al-rasul) menurut Ahmad al-Tijani adalah "Ia selalu rindu untuk bertemu dengan al-mabbûb (Nabi Muhammad saw), senantiasa mengagungkannya ketika disebut namanya dengan menampakkan perasaan khudu' (rendah hati) dan khusu'(khusuk), selalu mencintai Al-qur'an, sebab ia adalah firman Allah yang disampaikan melalui al-mabbub, dan terus menerus mempelajari sunnahnya. Jadi konsep syukur dan mababbah pada intinya harus dibuktikan dengan kecintaan terhadap segala sesuatu yang datang dari Nabi Muhammad saw melalui pengamalan terhadap segala sunnahnya. ${ }^{31}$

Selain itu bacaan salawat dalam wirid wazifah mempunyai fungsi membina dan mengarahkan murid untuk sampai pada tingkat bisa "menghadirkan" Rasulullah saw. Kaifiyat (cara) membaca salawat ini ada ketentuan khusus dari tarekat Tijaniyah, yaitu murid harus menundukkan kepala disertai perasaan khudu' (rendah hati) dan khusyu' (khusuk), sampai pada tingkat "menghadirkan" Rasulullah saw. ${ }^{32}$ karena menurut Ahmad al-Tijani orang yang mencapai tingkat ma'rifah kepada Allah harus terlebih dahulu melakukan pendekatan dengan Rasulullah saw.

Ketiga, Wirid Hailalah. Wirid ini dilaksanakan satu kali dalam seminggu, yakni pada setiap hari Jum'at setelah sembahyang Ashar dengan cara membaca zikir membaca lâ ilâha illa Allâh secara berjamaah sampai datangnya waktu magrib. ${ }^{33}$ Pengalokasian waktu hailalah pada hari Jum'at

\footnotetext{
${ }^{30}$ Ali Harazim, Jawabir al-Ma'ani...., h. 201-213.

${ }^{31}$ Ali Harazim, Jawahir al-Ma'ani...., h. 211 dan 202.

${ }^{32}$ Muhammad bin Abdullah, Al-Fath al-Rabbany...., h. 96.

${ }^{33}$ Ali Harazim, Jawahir al-Ma'ani...., h. 105
} 
setelah ashar berkaitan dengan waktu mustajab. Apabila wirid hailalah dilaksanakan munfarid (sendirian) karena ada halangan, maka harus dilaksanakan dengan ketentuan membaca ziker sebanyak 1600 kali atau minimal 1000 kali, dan tidak diharuskan sampai datangnya waktu magrib. ${ }^{34}$

Apabila dalam wirid lazimah ditekankan untuk membersihkan diri dari segala bentuk kotoran maksiat dengan modal dasar amalan istigfar, kemudian membina hubungan dengan rasul dengan jalan mengamalkan segenap sunnahnya bahkan sampai pada tingkat bisa "berhubungan" dengan Rasul saw. melalui amalan dasar salawat, sebagaimana terdapat dalam wirid warifah, maka dalam wirid hailalah, penekanannya ditujukan terhadap amalan ziker. Dalam wirid hailalah amalan ziker mempunyai fungsi menggerakkan ruh untuk membangun taubid zanqi (taubid rasa).

Dalam ajaran tasawuf, pengertian taubid (mengesakan Tuhan) bukan sekadar pengakuan tentang keesaan Tuhan melalui pendekatan dalil naqli (al-Qur'an dan hadis) dan aqli (akal) saja, melainkan dengan cara membebaskan diri dari ketergantungan dan hasrat terhadap selain Allah. Langkah-langkah yang mesti ditempuh untuk membangun taubid zauqi (tauhid rasa), hendaknya murid menghilangkan dan menghapuskan hasrat terhadap selain Allah. Maksudnya agar murid dapat berkonsentrasi menuju Tuhan. Untuk itu murid harus benar-benar berpaling dan menghilangkan dari pikiran dan perasaannya semua hal yang bersifat kemakhlukan.

Seseorang akan meraih taubid qauqi apabila segala pikirannya khusus terhadap keesaan Allah (muwabhid), pikirannya tidak menampakkan dirinya, yaitu dengan peniadaan semua sekutu terhadap makhluk Allah, dibarengi dengan pelaksanaan semua perintah-Nya, baik secara lahir maupun batin. Taubid zanqi yang "sempurna" akan tercapai apabila perhatian muwabhid pada dirinya telah hilang (fana'/sirna). Tegasnya tingkat kesempurnaan taubid akan dicapai apabila muwahbid sudah terserap atau menyatu ke dalam cahaya Tuhan. ${ }^{35}$ Dalam mengungkapkan taubid ini, Ahmad al-Tijani menggambarkan melalui ungkapan taubid li nafsib bi nafsib' 'an nafsib (untuk Allah, dengan Allah, dari Allah).

${ }^{34}$ Muhammad bin Abdullah, Al-Fath al-Rabbany...., h. 70.

${ }^{35}$ Ali Harazim, Jawabir al-Ma'ani...., h. 96. 
Amalan ziker dalam hailalah mendidik murid senantiasa dekat dengan Allah secara lahir dan batin, sehingga yang digoreskan di dalam hati dan yang diucapkan oleh lisan yakni zikr, berjalan seiring terus menerus ${ }^{36}$ dan bersifat reflek. Hal ini dimaksudkan untuk menolak setiap goresan jelek dalam pikiran. Sehingga menghasilkan pikiran yang jernih, bersih dari goresan-goresan selain Allah. Amalan ziker pada dasarnya merupakan dasardasar amalan yang harus dikembangkan oleh para murid untuk menata maqamat sampai mencapai derajat kewalian.

Dari paparan di atas menunjukan bahwa para wali (awliy â) mempunyai derajat yang bertingkat-tingkat sesuai dengan maqam yang sedang dilaluinya dan sebagai indikatornya Tuhan melepaskannya dari ikatan duniawi dan ia dibebaskan dari godaan-godan nafsu, dan dia menempatkan masing-masing pada derajat yang khusus sesuai dengan maqamnya, dan membukakan mereka pintu rahasia-Nya. Ahmad al-Tijani menyatakan bahwa, kewalian merupakan prinsip dan dasar tasawuf serta pengetahuan tentang Tuhan bertumpu pada kewalian. ${ }^{37}$

Tasawuf adalah disiplin melaksanakan taqarrub kepada Allah. Sedangkan cara atau metodenya disebut tarekat, sebab yang dimaksud dengan tarekat sebagaimana telah diungkapkan adalah jalan menuju Allah swt. Ada juga yang mengatakan bahwa tarekat disiplin dalam melaksanakan perintahNya dan menjauhi larangan-Nya disertai berpaling dari daya tarik kesenangan nafsu syahwat. Orang yang demikianlah yang sudah sampai pada maqam ma'rifah. Hal ini berarti bahwa kewalian adalah inti dari tasawuf. Karena yang dimaksud wali adalah seseorang yang disiplin melakukan ibadah (taqarrub) melalui tahapan maqamat sampai pada tingkat mengetahui rahasia-rahasia Tuhan, bahkan menurut sebagian sufi sampai pada tingkat ittihâd (penyatuan). Proses kewalian harus dibina melalui peniadaan segala hasrat baik yang bersifat duniawi maupun ukhrawi. Kaitannya dengan sikap dan sifat kewalian Ahmad al-Tijani mengatakan bahwa tasawuf adalah ilmu yang terpaut pada kalbu para wali karena mengamalkan al-Qur'an dan sunnah.

Tiga bentuk amalan wirid yang terdapat dalam tarekat Tijaniyah, yaitu wirid lazimah, wirid wazifah dan wirid hailalah, secara umum baru merupakan

\footnotetext{
${ }^{36}$ Ali Harazim, Jawabir al-Ma'ani...., h. 114.

${ }^{37}$ Ali Harazim, Jawahir al-Ma'ani...., h. 105.
} 
pemahaman nilai-nilai taubat, istiqamah, zubd dan taqwa. Maqamat ini merupakan dasar pengembangan nilai-nilai yang terkandung dalam amalan ziker. Maqamat inilah yang merupakan tahap pertama (awwal jur'ab) dari taubid zauqi (taubid rasa)

Perjalanan para sufi untuk bisa memantapkan bangunan taubid zauqi, sampai dengan Allah, atau maqam ma'rifah, bahkan maqam kewalian, bukanlah merupakan perjalanan yang pendek dan mudah, tetapi merupakan perjalanan panjang penuh tantangan. Atas dasar ini Ahmad al-Tijani memberikan peringatan kepada murid tarekat Tijaniyah, bahwa untuk bisa sampai kepada Allah, hendaklah tidak merasa cukup dengan amalan pokok yang terdapat dalam ajaran tarekat saja, tetapi hendaklah ditopang dengan amalan ikhtiyariyah (pilihan) yang terdapat dalam tarekat Tijaniyah, seperti do'a, salawat, dan bizb. Selain itu murid Tijaniyah tidak boleh melakukan ziarah kepada wali-wali Allah. Maksudnya dilarang ziarah apabila menimbulkan pertalian (ta'alluq) dengan selain Syekh Ahmad al-Tijani. Sedangkan yang dilarang adalah ziarah dengan tujuan mengambil amalanamalan tertentu, sebab mengambil ajaran wirid dari selain yang terdapat di dalam tarekat Tijaniyah, akan membawa dampak yang kurang menguntungkan bagi murid, yaitu memperlambat proses tercapainya sampai pada Allah.

Ikblas adalah menghilangkan segala sesuatu selain Allah, menghilangkan goresan hati dari keinginan terhadap nikmat-nikmat yang dijanjikan Allah, demikian juga sikap menghindar dari siksa Allah. Sebab pada dasarnya, nikmat dan siksa itu sendiri termasuk dalam katagori "selain Allah". Melaksanakan ibadah dengan dasar keinginan memperoleh nikmat surga dan menghindar dari siksa neraka, termasuk dalam katagori syirik al-agrad (musyrik tujuan). Amalan ziker yang terdapat dalam wirid hailalah, harus mampu menciptakan kesatuan arah dalam melaksanakan ibadah, yakni hanya tertuju pada Allah, dengan kata lain harus mampu menciptakan nilai-nilai ikhlas.

Kaitannya dengan pengamalan nilai-nilai ikhlas, murid harus menempatkan Allah dihatinya, tidak ada tempat buat selain Allah, hatinya harus diisi penuh dengan zikr pada Allah (al-wahid al-haq) dan murid harus bersikap tawakkul. ${ }^{38}$ Hakikat tawakkuladalah seseorang harus menjadi milik Tuhan, dan Tuhan harus menjadi miliknya. Ahmad al-Tijani memberikan

\footnotetext{
${ }^{38}$ Ali Harazim, Jawahir al-Ma'ani...., h. 129.
} 
pengertian ini dengan seseorang yang bertawak.kul, berarti ia menjadi sepenuhnya sebagai milik Tuhan, apapun kehendak Tuhan terhadapnya, dia tidak akan mempersoalkannya, sebab ia kepunyaan-Nya. Mengenai perlunya kepasrahan diri pada kehendak Tuhan, hal ini dimaksudkan agar murid puas dengan Tuhan dalam segala keadaan. ${ }^{39}$ Faham tawakkul ini dimaksudkan agar murid terikat sepenuhnya hanya kepada Allah. Sehingga nilai ziker menyatu dalam dirinya.

Apabila murid melaksanakan nilai-nilai tawakkul secara utuh, sehingga nilai ziker telah menyatu antara apa yang digoreskan dalam hatinya dengan segenap perbuatannya, maka dalam diri murid akan muncul sikap rida'. Pada posisi ini, murid telah terikat dengan Tuhan secara utuh. Sebab yang dimaksud dengan rida' ialah menerima dengan tenang semua ketentuan yang datang dari Allah. Kemudian secara bulat memasrahkan dirinya kepada apa yang menjaadi kehendak Tuhan. semua yang terjadi dan akan terjadi pada diri pribadinya diterima dengan segala senang hati, bahkan ia merasa senang menerima malapetaka sebagaimana ia merasa senang menerima nikmat. ${ }^{40} \mathrm{Hal}$ ini disebabkan oleh kesadarannya bahwa semua itu datang dari Allah semata. Semua yang berasal dari-Nya adalah bermanfaat dan hanya untuk kebaikan manusia. Dengan demikian segala yang terjadi pada dirinya disambut dengan hati terbuka bahkan dengan rasa bahagia, walaupun hal yang datang itu berupa bencana. Ketika dalam diri murid telah tertanam sikap rida' (rela) yakni menerima dengan rela segala ketentuan Allah, berarti murid telah terikat dengan Tuhan secara utuh.

Ketika dalam diri murid sudah tertanam nilai tuma'ninah secara utuh,

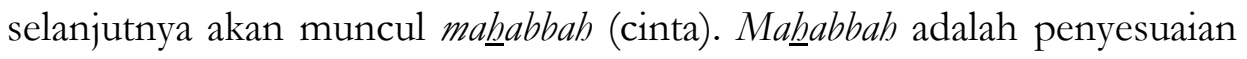
sifat-sifat dan akhlak-akhlak ilahiyah kedalam diri yang mencintai. Bila seorang murid cinta kepada Tuhan, maka perhatiannya hanya akan tertuju pada-Nya, dalam arti ia selalu berusaha menyesuaikan diri dengan akhlak ilahiyah. Hal ini seperti yang diungkapkan oleh Ahmad al-Tijani: "mababbah adalah segala penghapusan sifat-sifat yang mencintai dan penetapan yang dicintai (Tuhan).”41

\footnotetext{
${ }^{39}$ Ali Harazim, Jawabir al-Ma'ani...., h. 13.

${ }^{40}$ Ali Harazim, Jawahir al-Ma'ani...., h. 121.

${ }^{41}$ Ali Harazim, Jawabir al-Ma'ani...., h. 164.
} 
Selanjutnya Ahmad al-Tijani mengatakan bahwa apabila seseorang telah dipenuhi oleh rasa cinta kepada Tuhannya, maka berarti secara bulat hatinya telah diserahkan kepada-Nya, sehingga tidak ada satupun yang diharapkannya selain Allah. Seseorang yang selalu mengingat Tuhannya, sampai pada tingkat Tuhan menghilangkan tabir yang menghalangi dan menutupi-Nya. Ma $\underline{h} a b b a h$ pada tingkat ini hanya akan didapat oleh orang yang terbuka hijab (tabir). Kecintaan Tuhan terkandung dalam rahmat-Nya yang dilimpahkan kepada umat manusia. Cinta Tuhan terkandung dalam kemurahan-Nya kepada manusia, yaitu dengan memalingkan manusia dari berbagai pemikiran tentang segala sesuatu yang lain kecualli Tuhan, melimpahkan manusia dengan maqam yang tinggi melalui tajalli-Nya (penampakan lahir). Mábabbah hanya dapat dimanifestasikan dalam bentuk ketaatan seorang hamba untuk mengerjakan perintah Tuhannya setiap saat, berikut penyesuaian dengan akhlaknya, sampai pada tingkat Tuhan tajalli pada dirinya. Tandanya adalah murid dawam melaksanakan zikr tanpa ada paksaan. Dengan demikian segala sesuatu selain Allah tidak terlintas dalam hatinya. ${ }^{42}$

Pada maqam ini nilai ziker mengarahkan murid untuk terikat penuh kepada Allah, sebab maqam ini merupakan gerbang menuju tahapan ma'rifah (mengenal Allah). Apabila murid sudah mapan pada tahapan mababbah, maka ia akan meningkat menuju maqam murâqabah, "terbukanya hijab (tabir) untuk melihat rahasia-rahasia Allah”. Selanjutnya, apabila murid berada pada maqam muraqabah ini, ia harus memperhatikan hal-hal sebagai berikut:

Pertama, melaksanakan seluruh hak-hak Allah, lahir batin; Kedua, senantiasa mengarahkan ruh untuk berpaling dari selain Allah; Ketiga, hatihati terhadap isyarat-isyarat ruhani yang datang, sebab hal itu akan membelotkan tujuan yang sebenarnya; dan keempat, merahasiakan apa-apa yang tampak dari rahasia-rahasia yang didapat. Apabila murid telah mapan pada maqam murâqabah, maka selanjutnya ia akan meningkat ke maqam musyâhadah, yaitu "melihat rahasia-rahasia Allah tanpa tabir. Sebab pada posisi ini ruh telah suci dan bersih dari segala pengaruh wahm (dugaan), sehingga tidak ada sedikitpun yang tersisa selain rahasia ketuhanan, al-haq tajallî pada cermin ruh tanpa batas, tanpa keserupaan. ${ }^{43}$

\footnotetext{
${ }^{42}$ Ali Harazim, Jawahir al-Ma'ani...., h. 140.

${ }^{43}$ Ali Harazim, Jawahir al-Ma'ani...., h. 107.
} 
Telah dikatakan, ketika murid memasuki maqam murâqabah, berarti ia telah melihat rahasia Allah untuk selanjutnya ia memasuki maqam musyâhadah yaitu melihat Allah tanpa hijab. Ketika murid berada dimaqam murâqabah dan musyâhadah, dalam hal ini berarti murid telah memasuki maqam atau lingkup ma'rifah. Ma'rifah menurut Ahmad al-Tijani adalah "pengetahuan akan adanya keagungan Tuhan, melalui limpahan anwâr al-qudsiab (cahaya suci). ${ }^{44}$ Ma'rifah itu milik Tuhan, dan hanya diperoleh melalui limpahan rahmat-Nya. Ma'rifah hanya akan dilimpahkan oleh Tuhan kepada sufi yang dikehendaki-Nya. Tidak sembarang orang dapat mencapai atau menerima ma'rifah, hanya mereka yang terpilih saja yang mampu mendapatkannya. Tuhan yang memilih mereka untuk menerima anugrah dan memilih mereka untuk-Nya dan memberi mereka cinta-Nya. ${ }^{45}$ Anugrah yang diberikan Tuhan adalah merupakan rahmat yang dilimpahkan atas kehendak Tuhan sendiri. Ma'rifah yang dicapai hamba-hamba pilihan merupakan pengetahuan tentang Tuhan yang sempurna. Sesungguhnya ma'rifah yang sempurna tidak akan pernah ada. Karena keterbatasan manusia itu sendiri, sedangkan Tuhan merupakan zat yang tak terbatas, oleh sebab itu, tidak mungkin sesuatu yang terbatas dapat mengetahui yang tidak terbatas dengan segala kesempurnaanya. ${ }^{46}$

Puncak perjalanan tarbiyah rubani tarekat Tijaniyah adalah maqam murâqabah, musyâhadah dan ma'rifah yang diliputi fanâ' al-'fanâ'; yakni suatu kondisi ia akan kehilangan kesadaran terhadap segala sesuatu di sekitarnya, walaupun ia sendiri berada di lingkungan tersebut. Hal ini disebabkan tajalli Tuhan yang berpengaruh langsung pada dirinya. Gambaran puncak perjalanan ruhani tarekat Tijaniyah ini merupakan keadaan sakryang dialami oleh setiap sufi ketika mencapai puncak pengalaman tasawufnya, setelah itu ia akan kembali pada kesadaran atau hidup setelah mati. Ia akan memperoleh kembali kemampuannya dalam membedakan sesuatu, ia akan kembali kekehidupan normal sebagai seorang muslim biasa. ${ }^{47}$

\footnotetext{
${ }^{44}$ Ali Harazim, Jawahir al-Ma'ani...., h. 86 dan 112.

${ }^{45}$ Ali Harazim, Jawahir al-Ma'ani...., h. 87.

${ }^{46}$ Ali Harazim, Jawahir al-Ma'ani...., h. 205.

${ }^{47}$ Ali Harazim, Jawabir al-Ma'ani...., h.13.
} 
Setelah kehilangan kesadaran seorang sufi akan kembali kepada kondisi awalnya sebagaimana sebelum mengalami fanâ' al-fanâ'. Hal ini terjadi semata-mata atas kehendak Tuhan. Tuhanlah yang telah mengembalikan sufi tersebut pada sifat-sifatnya semula. Ini berarti fana adalah karunia Allah, dan bukan merupakan hal yang bisa diusahakan. ${ }^{48}$

\section{Penutup}

Demikianlah ajaran tasawuf Ahmad al-Tijani. Lewat ajarannya tentang proses pendidikan ruhani dapat dilihat tarekatnya sebagai upaya meraih posisi pewaris para nabi. Tampilnya seorang sufi di tengah masyarakat merupakan bentuk lain dari ketaatannya pada Allah dan rasul-Nya. Peranan para sufi begitu penting dalam kehidupan masyarakat dalam melakukan dakwah Islam. Para sufi tidak selayaknya jika hanya mementingkan kontemplasi dan zikr, lantas mengabaikan masyarakat yang memerlukan bimbingan []

\section{DAFTAR PUSTAKA}

Abdullah bin Husnain, Muhammad bin, (t.t). Al-Fath al-Rabbany fii ma yahtaju ilaibi l-Muriid al-Tijani, Surabaya: maktabah Sa'ad bin Nashir bin Nabhan.

Aceh, Abu Bakar, (1994). Pengantar Ilmu Tarekat, (Uraian tentang Mistik), Solo: Ramadhani.

Haeri, Syekh Fadlullah, (1994). Belajar Mudah Tasawuf, terj. Muhamad Hasyim Assegaf, Jakarta: PT Lentera Basritama.

Harazim, Ali, (1985). Jawahir al-Ma'ani wa Bulug al-Ma'ani, Mesir: Musthafa al-Babi al-Halabi.

Iskandar al-Barsany, Noer, (2001). Tasawuf Tarekat dan Para Sufi, Jakarta: Srigunting Raja Grafindo Persada.

${ }^{48}$ Ali Harazim, Jawahir al-Ma'ani...., h. 80. 
Mansur, M. Laily, (1999). Ajaran dan Teladan Para Sufi, Jakarta: PT Raja Grafindo Persada.

—, (1992). Tasawnf Islam, mengenal Aliran dan Ajaran, Banjarmasin: Unlam Press.

Projodikoro, (1997). "Jama'ah pengajian Tarekat Islamiyah Lempuyangan Yogyakarta" dalam Jurnal Penelitian Agama no 15 Th VI, Januari-April 1997.

Senali, Muhamad Saifulllah, al-Aziz, (2000). Tasawuf dan Jalan Hidup bagi Para Wali, Gresik: Putra Pelajar.

Ubaidah, Sayyid, (t.t). Mizab al-Rahmah fi al-Tarbiyah li al-tarekat al-Tijaniyah, Mesir: Maktabah Abd al-Hamid Ahmad.

Umar al-Futi, (t.t). Rimah fi Hiø̧b al-Rahim, Mesir: Mustafa al-Babi al-Halabi. Umarie, Bermawi, (1987). Sistematika Tasawnf, Solo: Ramadhani. 